\title{
Manfaat Terapi Pijat pada Konstipasi Kronis Anak
}

\author{
Muzal Kadim, Bernie Endyarni \\ Departemen Ilmu Kesehatan Anak, Fakultas Kedokteran Universitas Indonesia - RS Cipto Mangunkusumo, \\ Jakarta
}

Latar belakang. Konstipasi sering ditemukan pada anak dan menimbulkan masalah sosial maupun psikologi. Data menunjukkan 95\% kasus konstipasi anak merupakan konstipasi fungsional. Penelitian memperlihatkan dampak yang baik dari terapi pijat yang dihubungkan dengan berbagai kondisi dan penyakit pada anak. Tujuan. Melihat implikasi klinis terapi pijat terhadap pasien konstipasi kronis pada anak.

Metode. Penelitian prospektif intervensional dilakukan dengan randomisasi dan menggunakan kontrol, terhadap kasus konstipasi berusia 2-14 tahun di Divisi Gastroenterologi Departemen Ilmu Kesehatan Anak RSUPN Cipto Mangunkusumo sejak bulan Februari hingga Juni 2006.

Hasil. Jumlah subyek penelitian 16 orang terdiri dari 7/16 laki-laki dan 9/16 perempuan. Rerata umur subyek 4,1 tahun $(S B= \pm 1,3)$. Frekuensi buang air besar (b.a.b) pasien konstipasi fungsional mengalami peningkatan setelah diberikan terapi pijat. Jumlah pasien yang mengalami kicipirit, dengan tinja keras berkurang lebih banyak pada kelompok perlakuan dibandingkan kelompok kontrol. Jarak terlama antara b.a.b kelompok perlakuan mengalami penurunan yang lebih besar $(6,7 \pm 3,2$ hari menjadi 3,7 $\pm 1,7$ hari) dibandingkan kelompok kontrol $(5,2 \pm 2,4$ hari menjadi $3,3 \pm 1,0$ hari). Lama waktu b.a.b kelompok perlakuan berkurang lebih banyak $(21,2 \pm 18,2$ menit menjadi $14,37 \pm 8,6$ menit $)$ dibandingkan kelompok kontrol $(15,6 \pm 9,4$ menit menjadi 11,8+9,2 menit). Waktu yang dibutuhkan untuk terjadi perbaikan terhadap konstipasi kelompok perlakuan lebih singkat $(29,2 \pm 24,9$ hari) dibandingkan kelompok kontrol $(32,2 \pm 20,8$ hari $)$.

Kesimpulan. Terapi pijat dapat membantu mempercepat perbaikan konstipasi kronis fungsional. Sari Pediatri 2011;12(5):342-6.

Kata kunci: terapi pijat, konstipasi kronis, anak

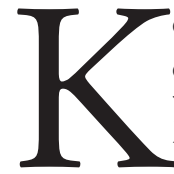

onstipasi merupakan keadaan yang sering ditemukan pada anak dan dapat menimbulkan masalah sosial maupun psikologi. ${ }^{1}$ Konstipasi ditemukan pada 3\% anak usia

\footnotetext{
Alamat korespondensi:

Dr. Muzal Kadim, Sp.A. Divisi Gastrohepatologi, Departemen Ilmu Kesehatan Anak FKUI-RSCM, Jl. Salemba No. 6 Jakarta 10430. Telp.: 021-3915665, E-mail: muzalk@yahoo.com
}

prasekolah dan 1\%-2\% anak usia sekolah. ${ }^{2}$ Berdasarkan patofisiologi, konstipasi dapat diklasifikasikan menjadi konstipasi akibat kelainan organik dan konstipasi fungsional. ${ }^{3,4}$ Klasifikasi lain membedakan konstipasi akut bila kejadian baru berlangsung selama 1-4 minggu dan konstipasi kronis bila keluhan telah berlangsung lebih dari 4 minggu. ${ }^{3-6}$ Dilaporkan 95\% kasus konstipasi anak yang dirujuk merupakan konstipasi fungsional. ${ }^{2,3}$ Ginkel $\mathrm{dkk}^{7}$ dalam penelitiannya 
memperlihatkan bahwa sepertiga pasien konstipasi kronis pada anak yang diikuti selama 5-8 tahun tetap mengalami konstipasi setelah masa remaja.

Terapi pijat telah dilakukan sejak ratusan tahun yang lalu di banyak negara khususnya di benua Afrika dan Asia. Beberapa penelitian menunjukkan dampak yang baik dari terapi pijat yang dihubungkan dengan berbagai kondisi dan penyakit pada anak. ${ }^{8,9}$ Terapi pijat juga merupakan terapi yang ekonomis dengan risiko yang relatif lebih rendah jika dilakukan sebagaimana mestinya. ${ }^{10}$

Saluran pencernaan dipersarafi oleh sistem saraf intrinsik dan ekstrinsik. Sistem saraf intrinsik menyebabkan usus dapat terus berfungsi tanpa perintah dari saraf ekstrinsik. Namun sistem saraf ekstrinsik dapat mengubah derajat aktivitas sistem saraf intrinsik. ${ }^{11,12}$ Para ahli di Eropa dan Amerika telah membuat suatu kriteria untuk menegakkan konstipasi fungsional yang dikenal dengan Kriteria Roma. Pada saat ini telah berlaku Kriteria Roma III yang merupakan penyempurnaan Kriteria Roma II.,13${ }^{17}$ Konstipasi kronis merupakan 1\%-3\% kasus rawat jalan pasien anak, ${ }^{2,3,7,18} 10 \%-15 \%{ }^{2,3}$ dan $25 \%$ kasus rujukan ke ahli gastroenterologi anak. ${ }^{19}$
Tujuan penelitian untuk mengetahui apakah terdapat implikasi klinis terapi pijat pada anak dengan konstipasi fungsional.

\section{Metode}

Penelitian prospektif intervensional dengan randomisasi dan menggunakan kontrol telah dilakukan untuk membandingkan implikasi klinis terapi pijat terhadap konstipasi pada pasien anak di Divisi Gastroenterologi Departemen Ilmu Kesehatan Anak RSUPN Cipto Mangunkusumo sejak bulan Februari hingga Juni 2006. Subyek dalam penelitian adalah semua pasien konstipasi berusia 2-14 tahun, menderita konstipasi fungsional sesuai dengan hasil anamnesis, pemeriksaan fisis, pemeriksaan penunjang, dan tidak memerlukan tindakan tertentu seperti pembedahan. Penentuan diagnosis konstipasi fungsional berdasarkan kriteria Roma III. Jumlah sampel masing-masing kelompok 11 subyek sehingga jumlah keseluruhan 22 subyek. Pada kelompok perlakuan diberikan terapi pijat dengan konsentrasi pada pijatan di daerah perut tiga kali 15

Tabel 1. Perbandingan kelompok kontrol dan perlakuan pada awal dan akhir penelitian

\begin{tabular}{|c|c|c|c|c|}
\hline \multirow[b]{2}{*}{ Karakteristik } & \multicolumn{2}{|c|}{ Kontrol } & \multicolumn{2}{|c|}{ Perlakuan } \\
\hline & $\begin{array}{l}\text { Awal } \\
(\mathrm{n}=8)\end{array}$ & $\begin{array}{l}\text { Akhir } \\
(\mathrm{n}=8)\end{array}$ & $\begin{array}{l}\text { Awal } \\
(\mathrm{n}=8)\end{array}$ & $\begin{array}{l}\text { Akhir } \\
(\mathrm{n}=8)\end{array}$ \\
\hline \multicolumn{5}{|l|}{ Teraba benjolan (n) } \\
\hline Ya & 4 & 0 & 3 & 0 \\
\hline $\begin{array}{l}\text { Tidak } \\
\text { Frekuensi b.a.b / mingou }\end{array}$ & \multicolumn{3}{|c|}{ Frekuensi b.a.b / minggu } & 8 \\
\hline $1 \mathrm{x}$ & 4 & 0 & 7 & 1 \\
\hline $2 \mathrm{x}$ & 2 & 1 & 0 & 2 \\
\hline $3 \mathrm{x}$ & 2 & 3 & 1 & 3 \\
\hline$>3 \mathrm{x}$ & 0 & 4 & 0 & 2 \\
\hline \multicolumn{5}{|l|}{ Konsistensi (n) } \\
\hline Keras & 8 & 3 & 8 & 1 \\
\hline Padat & 0 & 4 & 0 & 6 \\
\hline Lunak & 0 & 1 & 0 & 1 \\
\hline \multicolumn{5}{|l|}{ Bentuk tinja } \\
\hline Padat berbentuk & 3 & 8 & 6 & 8 \\
\hline \multicolumn{5}{|l|}{ Nyeri saat b.a.b } \\
\hline Ya & 8 & 4 & 8 & 5 \\
\hline Tidak & 0 & 4 & 0 & 3 \\
\hline \multicolumn{5}{|l|}{ Kicipirit } \\
\hline $\mathrm{Ya}$ & 4 & 3 & 7 & 2 \\
\hline $\begin{array}{l}\text { Tidak } \\
\text { Jarak terlama, b.a.b rerata/hari }\end{array}$ & $\begin{array}{c}4 \\
5,25 \pm 2,49\end{array}$ & $\begin{array}{c}5 \\
3,37 \pm 1,06\end{array}$ & $\begin{array}{c}1 \\
6,75 \pm 3,2\end{array}$ & $\begin{array}{c}6 \\
3,75 \pm 1,75\end{array}$ \\
\hline Lama defekasi, rerata $\pm S B$ / menit & $15,62 \pm 9,4$ & $11,87 \pm 9,2$ & $21,25 \pm 18,2$ & $14,37 \pm 8,6$ \\
\hline
\end{tabular}

Sari Pediatri, Vol. 12, No. 5, Februari 2011 
menit setiap hari, sedangkan kelompok kontrol hanya diberikan terapi standar konstipasi tanpa diberikan terapi pijat. Pemantauan dilakukan dengan mengisi kuesioner catatan harian selama dua bulan. Perubahan atau perbaikan pada konstipasi dinilai berdasarkan adanya perubahan atau perbaikan pada setiap komponen penilaian konstipasi jika dibandingkan sebelum dan sesudah penelitian.

\section{Hasil}

Jumlah subyek dalam penelitian ini sangat terbatas karena tergantung jumlah pasien konstipasi fungsional yang terdaftar di Divisi Gastroenterologi Departemen Ilmu Kesehatan Anak FKUI-RSCM selama periode waktu penelitian. Jumlah subyek 16 pasien dari perhitungan awal 22 pasien, terdiri dari 7/16 laki-laki dan 9/16 perempuan. Kepustakaan yang menyebutkan bahwa semasa usia prasekolah, angka kejadian konstipasi pada anak perempuan dan laki-laki seimbang. Walaupun pada usia sekolah, konstipasi lebih sering ditemukan

Tabel 2. Perbandingan adanya perubahan/ perbaikan antara kelompok kontrol dan perlakuan.

\begin{tabular}{|c|c|c|c|}
\hline Perubahan/perbaikan & Kontrol & Perlakuan & $p^{*}$ \\
\hline $\begin{array}{l}\text { Perabaan benjolan } \\
\text { Ada perubahan }\end{array}$ & 5 & 3 & 0,317 \\
\hline $\begin{array}{l}\text { Frekuensi b.a.b } \\
\text { Ada perubahan }\end{array}$ & 6 & 7 & 0,522 \\
\hline $\begin{array}{l}\text { Nyeri saat b.a.b } \\
\text { Ada perubahan }\end{array}$ & 4 & 2 & 0,302 \\
\hline $\begin{array}{l}\text { Konsistensi tinja } \\
\text { Ada perubahan }\end{array}$ & 5 & 6 & 0,590 \\
\hline $\begin{array}{l}\text { Bentuk tinja } \\
\text { Ada perubahan }\end{array}$ & 5 & 3 & 0,317 \\
\hline $\begin{array}{l}\text { Lama b.a.b } \\
\text { Ada perubahan }\end{array}$ & 5 & 4 & 0,614 \\
\hline $\begin{array}{l}\text { Pemeriksaan fisis } \\
\text { Ada perubahan }\end{array}$ & 4 & 6 & 0,302 \\
\hline $\begin{array}{l}\text { Foto polos abdomen } \\
\text { Ada perubahan }\end{array}$ & 5 & 4 & 0,614 \\
\hline $\begin{array}{l}\text { Kesulitan b.a.b lain } \\
\text { Ada perubahan }\end{array}$ & 0 & 1 & 0,302 \\
\hline $\begin{array}{l}\text { Kicipirit } \\
\text { Ada perubahan }\end{array}$ & 2 & 6 & 0,046 \\
\hline Lama perbaikan (minggu) & & & \\
\hline $\begin{array}{l}\leq 2 \\
>2\end{array}$ & $\begin{array}{l}1 \\
7\end{array}$ & $\begin{array}{l}4 \\
4\end{array}$ & 0,106 \\
\hline
\end{tabular}

*Uji chi square pada anak laki-laki. ${ }^{2}$ Rerata umur subyek adalah 4,1 tahun $(\mathrm{SB}= \pm 1,327)$ dengan sebaran usia antara 2,3 tahun sampai dengan 7 tahun. Lama pengamatan secara keseluruhan berkisar antara dua minggu hingga lebih dari dua bulan. Usia saat didiagnosis termuda saat usia 6 bulan dan tertua pada usia 7 tahun, sedang lama sakit berkisar 1 hingga 3 tahun.

Pada akhir penelitian tidak ada lagi pasien baik dari kelompok kontrol dan perlakuan yang mengalami bentuk tinja menyerupai kotoran kambing (Tabel 1). Hanya sekitar setengah pasien dari masing-masing kelompok yang masih merasakan nyeri saat b.a.b dari mulanya seluruh pasien mengalami nyeri saat b.a.b.

Jarak terlama antara b.a.b pada kelompok perlakuan mengalami penurunan yang lebih besar daripada pada kelompok kontrol. Lama defekasi pasien pada kelompok perlakuan mengalami penurunan yang lebih besar dibandingkan penurunan pada kelompok kontrol walaupun tidak bermakna (Tabel 2). Sedangkan pada kelompok kontrol rerata lama waktu perbaikan yang dibutuhkan $(32,2 \pm 20,8)$ hari. Rerata lama waktu perbaikan pada kelompok perlakuan $(29,2 \pm 24,9)$ hari.

\section{Pembahasan}

Konstipasi adalah ketidakmampuan melakukan evakuasi tinja secara sempurna yang tercermin dari tiga aspek, yaitu berkurangnya frekuensi berhajat dari biasanya, tinja lebih keras daripada sebelumnya dan pada palpasi abdomen teraba masa tinja (skibala), dengan atau tanpa disertai enkopresis (kecipirit). ${ }^{3,5}$ Beberapa gejala klinis lain yang sering dilaporkan pada anak dengan konstipasi, yaitu enkopresis, pengeluaran tinja dalam jumlah banyak secara periodik, nyeri saat defekasi, teraba masa pada abdomen dan rektum saat pemeriksaan fisis, serta nafsu makan menurun. ${ }^{1,2,6,20-23}$

Pada awal penelitian, hampir seluruh pasien pada kelompok perlakuan b.a.b hanya satu kali seminggu, namun pada akhir penelitian hanya $1 / 8$ pasien pada kelompok perlakuan. Sedangkan konsistensi tinja masing-masing kelompok pada awalnya adalah keras seluruhnya. Namun pada akhir penelitian, hanya $3 / 8$ dan 1/8 pasien masing-masing di kelompok kontrol dan perlakuan yang mengalami tinja dengan konsistensi keras, sedang selebihnya berkonsistensi padat dan lunak.

Berdasarkan Tabel 1, jumlah pasien yang kicipirit pada kelompok perlakuan mengalami penurunan yang 
lebih besar dibandingkan pada kelompok kontrol (dari 7/8 menjadi $2 / 8$ pada kelompok perlakuan dan 4/8 menjadi $3 / 8$ pada kelompok kontrol). Kicipirit (enkopresis) sering diartikan sebagai keluarnya tinja (di pakaian dalam) baik secara volunter maupun involunter, pada anak berusia di atas 4 tahun. Keluhan tersebut dapat muncul tanpa disertai kelainan organik. ${ }^{21}$

Secara keseluruhan, perilaku mengkonsumsi makanan berserat dan minuman yang cukup belum dapat memberikan perbaikan yang berarti. Hal tersebut antara lain karena hampir seluruh anak memang datang dengan keluhan asupan yang kurang baik kualitas dan kuantitas, serta orangtua mengeluh sulit memberi makan kepada anak, sehingga 15/16 pasien memang berstatus gizi kurang. Waktu intervensi dua bulan pada tiap anak sebenarnya belum dapat berhasil mengubah perilaku serta asupan makanan dan minuman pasien.

Terdapat beberapa pemeriksaan penunjang di bidang pencitraan yang penting untuk menegakkan konstipasi. Pemeriksaan paling sederhana adalah foto polos abdomen yang berguna untuk menilai ada atau tidaknya skibala, menunjukkan berapa banyak skibala, dan apakah terdapat kelainan pada tulang belakang. $22,24,25$

Pada penelitian kami, terdapat 2-3 orang pasien yang tidak mempunyai data foto polos abdomen oleh karena berbagai alasan. Berdasarkan hasil foto polos abdomen tampak bahwa seluruh pasien mengalami perbaikan gambaran foto polos abdomen. Walaupun jumlah pasien yang mempunyai gambaran skibala pada kolon asenden lebih banyak di kelompok perlakuan, namun pada akhir pemeriksaan tidak ada lagi yang memiliki skibala di kolon asenden. Sehingga secara kasar sebenarnya kondisi foto polos abdomen pasien kelompok perlakuan mengalami perbaikan yang lebih banyak dibandingkan kelompok kontrol.

Total nilai perbaikan dan perubahan konstipasi pada kedua kelompok tidak jauh berbeda yaitu $6,1 \pm 2,5$ poin pada kelompok kontrol dan $5,8 \pm 2,1$ poin pada kelompok perlakuan. Hal tersebut disebabkan oleh karena yang dinilai adalah perubahan atau perbaikan saja tanpa melihat tingkat beratnya masalah pada awal dan akhir penelitian.

Jika dilihat berdasarkan perubahan/perbaikan yang terjadi pada kelompok kontrol dan kelompok perlakuan tidak terlihat perubahan/perbaikan yang bermakna jika dibandingkan antara kedua kelompok $(p>0,05)$. Keadaan ini dapat diseb.a.bkan oleh jumlah subyek yang sedikit dan keadaan awal subyek yang bervariasi pada kedua kelompok.

Perubahan yang terjadi pada kelompok perlakuan tidak berbeda bermakna jika dibandingkan kelompok kontrol. Namun secara keseluruhan, keadaan pada kelompok perlakuan mengalami perubahan yang lebih baik jika dibandingkan dengan kelompok kontrol. Penelitian kami tidak menilai perubahan perilaku tetapi hanya melihat hubungan antara pemberian terapi pijat terhadap pola defekasi pasien konstipasi fungsional.

\section{Kesimpulan}

Frekuensi buang air besar pasien konstipasi fungsional mengalami peningkatan setelah diberikan terapi pijat. Jumlah pasien yang mengalami kicipirit, tinja berkonsistensi keras, berkurang lebih banyak pada kelompok yang mendapat terapi pijat dibandingkan kelompok kontrol. Jarak terlama antara b.a.b, lama b.a.b kelompok yang diberikan terapi pijat mengalami penurunan yang lebih besar dibandingkan kelompok kontrol. Waktu yang dibutuhkan untuk terjadi perbaikan terhadap konstipasi kelompok terapi pijat lebih singkat dibandingkan kelompok kontrol. Terapi pijat dapat membantu mempercepat perbaikan konstipasi kronis fungsional.

\section{Daftar pustaka}

1. Benninga MA. Constipation and faecal incontinence in childhood (thesis). Amsterdam. University of Amsterdam, 1994:13-40.

2. Felt B, Coran A, Kochhar P, Marcus S, Olson A, Wise C, dkk. Idiopathic Constipation and Soiling in Children. UMMC Idiopathic Constipation and Soiling Guideline, September, 1997.

3. Firmansyah A. Konstipasi pada anak. Dalam: Trihono P, Syarif DR, Amir I, Kurniati N, penyunting. Current management of pediatric problems. Jakarta: Dept IKA FKUI;2004.h.80-8.

4. Faigel DO. A clinical approach to constipation. Clin Cornerstone 2002;4:11-21.

5. Firmansyah A. Konstipasi pada anak.Sari Pediatri 1994;2:51-5.

6. Endyarni B, Hegar B. Konstipasi fungsional. Sari pediatri 
2004;6:75-80.

7. Ginkel RV, Reitsma JB, Buller HA, Wijk MP, Taminiau JAJ, Benninga MA. Childhood constipation: longitudinal follow-up beyond puberty. Gastroenterology 2003; 125:357-63.

8. Field T, Hernandez-Reif M, Diego M. Massage therapy for pediatric problems. Dalam: Field T. Touch and massage in early child development. Johnson and Johnson Pediatric Institude; 2004.h.239-54.

9. Diego MA, Field T, Hernandez-Reif M. Vagal activity, gastric motility and weight gain in massaged preterm neonates. J Pediatr 2005;147:50-5.

10. Polubinski JP, West L. Implementation of a massage therapy program in the home hospice setting. J Pain Symptom Manage 2005;30:104-6.

11. Gender AR. Bowel regulation and elimination. Dalam: Hoeman SP, penyunting. Rehabilitation nursing process and application. St. Louis: Mosby; 1996.h.452-75.

12. Cardenas DD, Mayo ME, King JC. Urinary tract and bowel management in the rehabilitation setting. Dalam: Braddom RL, penyunting. Physical medicine and rehabilitation. Philadelphia: WB Saunders Company; 1996.h.555-79.

13. Whorton J. Civilisation and the colon: constipation as the "disease of diseases". BMJ 2000;321;1586-9.

14. Wald A. Advances in gastroenterology: Constipation. Med Clin North Am 2000;84:1231-46.

15. Arce DA. Problem-oriented diagnosis: Evaluation of Constipation. American Family Physician 2002;65: 2283-90.

16. Rao SS. Constipation: evaluation and treatment. Gastroenterol Clin North Am 2003;32:659-83.

17. Thompson WG, Longstreth GF, Drossman DA, Heaton KW, Irvine EJ, Muller-Lissner SA. Functional bowel disorders and functional abdominal pain. Gut 1999; 45: 43-7.

18. Fishman L, Lenders C, Fortunato C, Noonan C, Nurko S. Increased prevalence of constipation and fecal soiling in a population of obese children. J Pediatr 2004;14:253-4.

19. Burnett CA, Juszczak E, Sullivan PB. Nurse management of intractable functional constipation: a randomized controlled trial. Arch Dis Child 2004;89:717-22.

20. Kearney DJ, Mc Quaid KR. Approach to the patient with gastrointestinal disorders. Grendell JH, McQuaid KR, Friedman SL, penyunting. Current diagnosis and treatment in gastroenterology. Connecticut:Prentice Hall International Inc; 1996.h.17-23.

21. Di Lorenzo C. Constipation. Dalam:Hyman PE, penyunting. Pediatric gastrointestinal motility disorders. New York: Academy professional information services. Inc., 1994.h.129-41.

22. Buller MA, Ginkel VR, Benninga MA. Constipation in children, pathophysiology and clinical approach. Dalam: Soetjiningsih, Sukardi R, Subanada IB, Sanjaya P IGN, Mahalini DS, penyunting. Proceedings Book $12^{\text {th }}$ National Congress of child health, 2002:333-40.

23. Wyllie R. Motility Disorders and Hirschsprung disease. Dalam: Behrman RE, Kliegman RM, Arvin AM, penyunting. Nelson Textbook of Pediatrics. Edisi ke-16. Philadelphia: WB Saunders Company; 2000.h.113844.

24. Devroede G. Constipation. Sleisenger MH, Fordtran JS, penyunting. Dalam: Gastrointestinal disease; pathophysiology, diagnosis and management. Edisi ke 4. Philadelphia:WB Saunders Company;1989.h.341-61.

25. Baucke VL. Chronic constipation in children. Gastroenterology 1993;105:1557-64. 